\title{
APRESENTAÇÃO/PRESENTATION SUBJETIVIDADE E ALTERIDADE: ENCONTROS AUTORAIS
}

\author{
“[...] o nascimento do leitor deve pagar-se com a morte do Autor."
}

(Roland Barthes)

Os dez artigos de nossa terceira edição de 2017 podem ser agrupados em cinco conjuntos que fazem convergir grandes temas contemporâneos: o feminino/feminismo (dois artigos), o letramento escolar (quatro artigos), a teoria de gênero (um artigo), os estudos de mídia (dois artigos) e o olhar jurídico (um artigo). Figuram aí os constantes encontros e desencontros nas práticas dos vários campos sociais, mostrando em traços mais ou menos fortes o que se concebe como fluidez em nossas sociedades. Mantivemos parcialmente nosso foco na subjetividade e na alteridade em seu movimento espiralado, tal como perspectivado na edição dois, mas mudamos o ângulo de reflexão para um tópico que será tomado em sua qualidade crítica: a autoria, categoria que amarra o conjunto, até mesmo porque a injunção à produtividade, com seus ângulos positivos e negativos, leva ao desejo de um julgamento de autoria, pela produção a ser submetida, olhada, avaliada, e, finalmente, publicada, havendo mérito. Não se trata de definição de lugares, como se fora um concurso classificatório, mas especificamente de como sentimos e interpretamos ou somos sentidos e interpretados, uma vez submetidos a parâmetros sociais que nos incluem ou rejeitam, agora ou adiante, neste ou naquele lugar.

Dentre as múltiplas possibilidades de olhares para a autoria, escolhemos partir de um que se aplica sobre crise, pontuada em artigo de Rodrigo Ielpo (2013) ${ }^{1}$. E podemos continuar relembrando considerações feitas em edições anteriores sobre nosso modo político de vida - ideológico, imaginário -, no qual se engendram encontros e desencontros, em que as linguagens estão sempre presentes - e aqui tão destacadas, em nosso modo científico e pedagógico de tratamento dos temas. A autoria, agora, não é um tema dos artigos: é uma figura que sobrevoa todos eles, com um relevo especial, implicando saberes especiais - no caso, saberes em construção pelos pesquisadores. E não apenas sobrevoa, como uma cobertura que se pretende protetora, mas também é assombrada: "há um fantasma que assombra essa caminhada [desenvolvimento da autoria]: o plágio, que pode intervir sub-repticiamente, minando o efeito-autor." (FURLANETTO, 2015, p. 171-172) 2 .

De que crise se trata, em Ielpo? "Trata-se da crise de uma morte, mais especificamente, a morte do autor, pois que na instância do discurso não só a vida entra

\footnotetext{
${ }^{1}$ IELPO, Rodrigo. Da crise de uma morte aos impasses da ressurreição. Revista Criação \& Crítica, n. 11, p. 48-60, nov. 2013.

${ }^{2}$ FURLANETTO, M. M. A "morte do autor", a leitura de outrem e a construção autoral. In: FLORES, G. G. B.; NECKEL, N. R. M.; GALLO, S. L. (Org.) Análise de Discurso em rede: cultura e mídia. V. 1. Campinas (SP): Pontes, 2015. p. 155-173.
} 
em crise." Ielpo associa a ideia de "morte elocutória do poeta" na perspectiva de Mallarmé e a teorização da "morte do autor" em Roland Barthes (BARTHES, 2004) ${ }^{3}$, em correspondência com a morte do sujeito na óptica do humanismo, conforme Foucault. Ielpo propõe problematizar essas mortes, mesmo porque entende que há regimes diferentes de autoria (lembrando Borges) - no caso, ele está refletindo mais de perto sobre literatura, que tem seus próprios conflitos, específicas linhas de tensão ao refletir sobre os processos de subjetivação. O trabalho de Barthes (publicado em 1968) entra na linha de questionamento do pensamento humanista na França dos anos 1960, junto a outros autores (Foucault, Derrida, Lacan...). Isso significou um outro modo de olhar a linguagem, pensada até ali, prioritariamente, como meio de comunicação, e o sujeito como ser consciente (origem, intenção) e fiador do sentido.

Em uma exploração de autores, tanto estrangeiros como brasileiros, especialmente com respeito a autobiografias, mas também ficção, Ielpo aponta um deslizamento do Eu por efeito de dramatização e de ficção, provocando a percepção de des-conhecimento desse Eu (ego), que não aparecia senão como efeito da própria escritura. Seriam fenômenos como este que indicariam a subjetivação mediada, e não de modo autônomo. E então, remetendo a Derrida, diz que essa "ética da escritura" levaria "a essa espécie de passagem de um sujeito-autor a um autor-sujeito, ato que desloca a questão da identidade como descoberta para a identidade como criação. Dessa forma, a 'voz' desse autor-sujeito só poderia captar-se em movimento, no movimento.” (IELPO, 2013, p. 53-54).

Notemos também: Derrida (2002, p. 24) ${ }^{4}$ conta, em A escritura e a diferença, que Merleau-Ponty escreveu: "As minhas palavras surpreendem-me a mim próprio e me ensinam o meu pensamento". E Derrida comenta: “É por ser inaugural, no sentido jovem deste termo, que a escritura é perigosa e angustiante. Não sabe aonde vai, nenhuma sabedoria a protege dessa precipitação essencial para o sentido que ela constitui e que é em primeiro lugar o seu futuro." (p. 24-25, grifo do autor).

Ielpo reconhece que, assumindo a ideia de autor-sujeito captado pelo movimento, "a noção de anterioridade do autor em relação ao escrito encontra-se em xeque" (p. 54), o que convergiria para o que dizem Barthes e Foucault, embora com ressalva quanto a este: Foucault escreveu que no espaço da escritura "o sujeito não cessa de desaparecer". Complementemos, revisitando Foucault: "Na escrita, não se trata da manifestação ou da exaltação do gesto de escrever, nem da fixação de um sujeito numa linguagem: é uma questão de abertura de um espaço onde o sujeito de escrita está sempre a desaparecer." (FOUCAULT, 1997, p. 35) $)^{5}$. E, um pouco adiante, ele escreve que a relação da escrita com a morte manifesta-se "no apagamento dos caracteres individuais do sujeito que escreve; por intermédio de todo o emaranhado que estabelece entre ele próprio, ele retira a todos os signos a sua individualidade particular; a marca do escritor não é mais do que a singularidade da sua ausência; é-lhe necessário representar o papel do morto no jogo da escrita." (1997, p. 36-37). Entende Ielpo que, para além do jogo abertura/desaparecimento, a escritura estaria a serviço de um sujeito que, não podendo

\footnotetext{
${ }^{3}$ BARTHES, Roland. O rumor da língua. São Paulo: Martins Fontes, 2004 [1984].

${ }^{4}$ DERRIDA, Jacques. A escritura e a diferença. 3. ed. São Paulo: Perspectiva, 2002 [1967].

${ }^{5}$ FOUCAULT, Michel. O que é um autor? 3. ed. Lisboa: Vega, 1997 [1969].
} 
constituir-se como anterioridade, também não poderia simplesmente apagar-se, como escreveu Foucault. É assim que, fazendo remissão a Derrida, a tensão do autor-sujeito pode se inscrever pelo traço, marca do passado (em reatualização constante) e abertura para o futuro, sem identidade instalada definitivamente.

Nesse passo é que Ielpo, analisando de perto as tensões da obra de Georges Perec, escritor francês (1936-1982) conhecido por sua literatura experimental, opta pela posição, reconsiderando Foucault: "nem desaparecimento, nem retorno do sujeito." (2013, p. 57). A questão seria verificar como a crise é encenada subjetivamente na literatura, e um lugar paradigmático para isso seria a autobiografia e o testemunho, por exemplo. Em acréscimo, poderíamos pôr em jogo a análise da obra Valis, de Philip Dick ${ }^{6}$, considerado um autêntico visionário da ficção norte-americana. Sua narrativa é quase autobiográfica. $\mathrm{O}$ quadrinho (de Robert Crumb, de 1986) que narra a experiência mística de Dick (em 1974) deu origem ao romance, conforme registram o tradutor da obra, Fábio Fernandes, e os editores da Aleph. O romance apresenta o alter ego de Dick narrando essa experiência.

Entretanto, há duas facetas a considerar para que possamos incluir a compreensão fundamental das relações implicadas na autoria, que relembramos, de modo genérico, remetendo a Norbert Elias $(1994)^{7}$, na obra A sociedade dos indivíduos: o autor destaca que é imperioso que nos libertemos da compulsão em opor indivíduo e sociedade para entendermos que o que cria a subjetividade são os laços de interdependência das pessoas, em processo fundamentalmente alteritário.

Uma faceta diz respeito ao que Foucault responde a seus interlocutores durante a exposição feita em 1969 da comunicação $O$ que é um autor? - não que já não houvesse ciência de que a ideia de sujeito individual deveria ser substituída pela de sujeito coletivo ou transindividual, como admite Lucien Goldmann, um dos interlocutores de Foucault. Ele [Foucault] precisa fazer-se compreender: "não disse que o autor não existia; não disse e admiro-me que o meu discurso se tivesse prestado a semelhante contra-senso." (FOUCAULT, 1997, p. 80); "o autor deve apagar-se ou ser apagado em proveito das formas próprias aos discursos." (p. 80). Assim, o que lhe parecia fundamental é o que se poderia descobrir com a regra do desaparecimento do autor. E a resposta era: "o jogo da função autor" (p. 81), o modo como ela se exercia, culturalmente falando. A partir daí volta à questão da morte do homem, que lhe é associada: "Não se trata de afirmar que o homem está morto [...], trata-se, a partir desse tema, [...] de ver de que maneira e segundo que regras se formou e funcionou o conceito de homem." (p. 81). Ainda um pouco adiante, na troca que se efetivava, ele também insistiu em que não estava reduzindo o autor a uma função, mas "analisava a função no interior da qual qualquer coisa como um autor podia existir.” (p. 83).

A outra faceta remete a uma complementação no trabalho de Barthes sobre a morte do autor, e que nos interessa em função do campo de autoria de que se trata aqui: não da autoria literária, referente a escritores que podem se consagrar, mas da autoria em ciência e daquela que se supõe passível de desenvolvimento na escola, ampliando o conceito de função-autor de Foucault. Analisando esse material de Barthes e outros a ele associados,

\footnotetext{
${ }^{6}$ DICK, Philip K. Valis. 2. ed. São Paulo: Aleph, 2014 [1981].

${ }^{7}$ ELIAS, Norbert. A sociedade dos indivíduos. Rio de Janeiro, Zahar, 1994 [1987].
} 
e posicionando-se no campo pedagógico, Furlanetto $(2015$, p. 157) propõe pensar "a produção e o efeito de autoria no espaço entre 'a morte do autor' e o 'nascimento do autor'; e refletir sobre autorar ( $\mathrm{eu}$ ) e ler (outro) e seus conflitos." O problema reside nesta constatação de Barthes em texto de 1970: Escrever a leitura: "faz séculos que nos interessamos demasiadamente pelo autor e nada pelo leitor"; "o autor é considerado o proprietário eterno de sua obra, e nós, seus leitores, simples usufrutuários" (BARTHES, 2004, p. 27). Isso não significa, certamente, que deixaremos de considerar a existência de direitos autorais e as preocupações com qualquer tática para burlar esses direitos; contudo, não só em literatura reina o autor como personagem moderna, como pessoa e como obra - que são produtos da sociedade moderna, como admite Barthes -, como em qualquer outro campo em que seja possível reconhecer, nesse regime, a produção autoral. A visão em pauta se deve às ciências humanas, e o conflito resultante precisa ser administrado. $\mathrm{O}$ que Barthes faz é mostrar que "o texto é um tecido de citações, oriundas dos mil focos da cultura." (p. 62). Afastado o Autor, afasta-se a leitura única, direcionada; o todo da escritura só será reunido no lugar do leitor; a unidade do texto estaria em seu destino, que não é pessoal: é um alguém, diz Barthes, que vai reunir todos os traços deixados pela escritura - e isso significa que ele não é passivo, mas produz sentido. Sem essa rede sequer se constitui o que podemos chamar imagem de autor - ou ainda efeito-autor.

É por esse caminho que pensamos na teia delicada que é tecida do lugar da autoria, com os regimes autorais envolvendo formas subjetivas, enlaçadas inevitavelmente àqueles que, praticando a leitura, interpretam, retomam, produzem, recriam - nós todos que nos posicionamos de um e de outro lado, ensaiando a própria morte e deixando, ainda assim, traços, cicatrizes para uma próxima ou distante arqueologia.

Esta reflexão poderia, talvez, acrescentar algo às experiências de autoria trazidas nesta edição da Linguagem em (Dis)curso, bem como às experiências de leitura, em seu invitável atravessamento.

\section{Os Editores}

